\title{
Effect of Family Income on Knowledge, Attitude and Practices Regarding Breast Cancer and its Screening Methods Amongst Women of Lahore, Pakistan
}

\author{
Ayesha Rizwan, Zikria Saleem, Saleha Sadeeqa ${ }^{1 *}$ \\ Punjab University College of Pharmacy, Lahore, Pakistan. \\ ${ }^{1}$ Institute of Pharmacy, Lahore College for Women University, Lahore, Pakistan.
}

\begin{tabular}{|c|c|}
\hline ARTICLE INFO & ABSTRACT \\
\hline Article history: & \multirow{8}{*}{$\begin{array}{l}\text { The study aimed to examine the effects of total family income of a household on the knowledge, attitude and } \\
\text { practices regarding breast cancer and its screening methods amongst women of Lahore. A cross-sectional survey } \\
\text { was conducted on } 504 \text { randomly selected women using a self-administered, structured questionnaire. The study } \\
\text { suggested a direct relationship between the household income and the knowledge of women. Mean knowledge } \\
\text { was } 37.8 \% \text { in the group having an income of PKR }<10,000 \text {. The groups having incomes PKR10,000-30,000, } \\
\text { PKR30,000-60,000 and PKR }>60,000 \text { had mean knowledge } 44.4 \%, 62.7 \% \text { and } 66.47 \% \text { respectively. Attitudes } \\
\text { and practices were independent of the income. However, participants with a monthly income of PKR }>10,000 \\
\text { had a general trend of better breast self-exam practices. All the groups almost equally realized the importance of } \\
\text { performing BSE, although, the overall practice score was low (35.4\%). Findings suggested that overall } \\
\text { knowledge was relatively weak in all participants, being lowest in the low-income groups. }\end{array}$} \\
\hline Received on: $17 / 01 / 2017$ & \\
\hline Accepted on: 14/07/2017 & \\
\hline Available online: $30 / 08 / 2017$ & \\
\hline Key words: & \\
\hline Knowledge, Attitude, & \\
\hline Practices, Breast Cancer, & \\
\hline Screening. & \\
\hline
\end{tabular}

\section{INTRODUCTION}

Breast cancer is the most frequently diagnosed cancer among women worldwide and is the most common cancer overall only second to lung cancer (Ferlay et al., 2010) There is a higher incidence rate of breast cancer is Western European countries as compared to that of Eastern Asian or African countries (Jacques et al., 2010; DeSantis et al., 2011). However, there is a significantly higher survival rate of the patients diagnosed with the disease in Western European countries compared to that of Asian or African counties(Ma and Jemal, 2013). This is attributed to better screening and treatment facilities in the developed world. There are several contributing risk factors to the disease. Well-established risk factors include;

\footnotetext{
* Corresponding Author

Saleha Sadeeqa, Lahore College for Women University,

Lahore, Pakistan.Email: salehasadeeqa @ gmail.com

Phone: +923054122345
}

older age, family history of the disease, exposure to radiation, use of oral contraceptive pills, first childbirth at an age greater than 30 years and irregular menstrual cycles among others (McPherson et al., 2000). A survey of the U.S. population showed that $47 \%$ of the total reported cases indicated a strong connection to these established risk factors (Madigan et al., 1995). Studies showed a huge gap between the acceptance of the importance of BSE education and the actual awareness of the procedures and methods of BSE in the masses. This problem is particularly true for Asian and African countries (Montazeri et al., 2008; Parsa and Kandiah, 2005; Sim et al., 2009). The lack of knowledge, however, did not always present as the reason for the lack of BSE practice. Studies among the nurses of Lagos, Nigeria; school teachers of Buraidah, Saudia and lady health workers of Tehran, Iran suggested that regardless of women being educated in the field of science, they had little knowledge of the breast cancer screening methods (Odusanya, 2001; Dandash and Al-Mohaimeed, 2007; Haji-Mahmoodi et al., 2002). 
Religious misconceptions, social pressures, cultural barriers, lack of facilities and misguided beliefs contribute towards the lack of breast cancer screening efforts and delayed helpseeking attitudes of a lot of ethnic groups in different countries (Azaiza, 2006; Flórez et al., 2009; Lannin et al., 2002; Mitchell et al., 2002; Underwood, Shaikha et al., 1998). Older women, who are at a greater risk of developing the disease (Colditz and Rosner, 2000), are also surprisingly, among the groups who are least aware of the identifying symptoms. Limited statistical data is available for the incidence rate of the disease in Pakistan. A 1995-1997 survey shows that breast cancer is not only the most commonly reported cancer in Pakistani females but, Pakistani females also show a significantly higher incidence rate of the disease compared to any other Asian country except for Israel (Bhurgri et al., 2000). The average reported age of the disease occurrence is also about 10 years younger in the Asian (and hence Pakistani) population compared to any other in the world (Agarwal et al., 2007).

Breast Self-Exam and other screening methods are directly related to early detection which leads to better survival rate (Jatoi, 1999; Tabar et al., 1985). The role of education in minimizing the mortality rate of the disease cannot be stressed enough. There have not been such studies in for the population of Lahore. The effect of household income on the knowledge and practices has also not been explored yet. Since household income directly influences the access to health care facilities in developing countries (Peters et al., 2008) like Pakistan, it is of value to study the influence it can have on knowledge attitude and practices regarding breast cancer and its screening methods.

\section{MATERIALS AND METHODS}

A community based descriptive cross-sectional study was carried out to assess the knowledge, attitude and practices regarding breast cancer and its screening methods in women of Lahore, Pakistan. The study was completed over a period of 5 months from February 2016 to June 2016. Effect of the total household income on the knowledge, attitude and practices of 550 women selected by non-probability convenient sampling, between the ages of 18 and 60 with no prior history of breast cancer were assessed using a self-administered questionnaire (in English and Urdu). The participants signed an informed consent before taking part in the study

The participants were divided into four socio-economic groups; those with the monthly household income of less than PKR 10,000 (class 1), income PKR 10,000-30,000 (Class2), income PKR 30,000- 60,000 (Class3) and income more than PKR 60,000 (Class4). The questionnaire collected information regarding the demographic characteristics, knowledge about what breast cancer is, its risk factors, knowledge about breast self-exam, practices regarding the frequency of BSE and attitude towards the prevention of the disease.

The score for knowledge, attitude and practices were calculated by giving 1 for a 'yes' answer and a 0 for both a 'no' and a 'don't know' answer. The Likert scale score was assigned as
5 for 'strongly agree', 4 for 'agree', 3 for 'neither agree nor disagree', 2 for 'disagree' and 1 for 'strongly disagree'. The total score for knowledge, attitude and practices was then calculated for each participant and an average knowledge, attitude and practice score was calculated for all participants.

Data was analyzed using SPSS version 22.0. Descriptive statistics was applied for the analysis of demographic data and for the association of demographics with the mean scores of knowledge, attitude and practices, chi- square test was performed. Chi- squared probability value equal to or less than 0.05 was considered as significant.

\section{RESULTS}

The questionnaire was given to 550 women, of which 504 returned it with all questions answered, giving a response rate of $91.6 \%$.

\section{Socio-demographic characteristics of study participants}

Mean age of the participants was 31.5 years with the age ranging from 18 years to 60 years. $53 \%$ of the women were never married, while $47 \%$ were at least married once. $6.9 \%$ of the women belonged to the socio-economic class 1 , with the monthly household income less than PKR 10,000, 17.5\% of Class2, 29.8\% of Class 3 and $45.8 \%$ of Class $4.13 .7 \%$ women had no formal education while $4 \%$ had a primary education. $6 \%$ have had a matriculation degree, $14.3 \%$ a college degree and $62.1 \%$ had at least an undergrad degree. Breast cancer family history was found in $25.2 \%$ of the women.

\section{Knowledge about breast cancer}

The mean knowledge scores were $37.8 \%, 44.4 \%, 62.7 \%$ and $66.47 \%$ in socio-economic classes $1,2,3$ and 4 . The overall knowledge score in all 504 participants was only 52.9\%. More than $90 \%$ people from all four classes knew what breast cancer was and that it can be treated but only $68 \%, 71 \%, 76 \%$ and $85.4 \%$ from classes 1,2,3 and 4 knew that a Breast Self-Exam can decrease the mortality rate by early diagnosis. However, even fewer people knew how to perform a BSE with only $22 \%$ from Class $1,48 \%$ from Class 2, 52\% from Class 3 and $57.2 \%$ from Class $4.33 \%$ women from class 1 knew what a mammogram was, $48 \%$ from Class $2,46.5 \%$ from Class 3 and $52 \%$ from Class 4.

\section{Knowledge about breast cancer risk factors}

Breastfeeding children decreasing the risk of breast cancer was most commonly known among all other risk factors with $84 \%$ from class $1,71.6 \%$ from class $2,53 \%$ from class 3 and $29 \%$ from class 4 knowing about it. Use of oral contraceptives being a risk factor was known in $34 \%, 52 \%, 63.5 \%$ and $82 \%$ of the people from classes 1, 2, 3 and 4 respectively. Age and Sun radiations as risk factors were also comparatively well-known with $49 \%$ and $32 \%$ from class $1,53 \%$ and $69 \%$ from class $2,82 \%$ and $75.7 \%$ from class 3 and $62.3 \%$ and $78.4 \%$ from class 4 knowing about them. Age of start of menstrual cycle and age at the birth of 
the first child as risk factors were only known in about $50 \%$ or fewer people in all classes. Obesity as a risk factor was also not well known, with only $26 \%$ participants from class $1,56 \%$ from class $2,66 \%$ from class 3 and $42 \%$ from class 4 knowing about it.

\section{Attitudes and practices towards breast cancer screening}

The attitude scores for Classes 1, 2, 3 and 4 were found to be $84.85 \%, 90.68 \%, 89.8 \%$ and $87.6 \%$ respectively. On the other hand, the practice scores were $32.1 \%, 37 \%, 36.42 \%$ and
$36.1 \%$ for the four classes. Less than half of the participants had ever performed a Breast Self-Exam from all four classes, with $45.7 \%$ in class $1,50 \%$ in class $2,43.2 \%$ in class 3 and $34.8 \%$ in class 4 . Of these, very few people performed monthly breast selfexams with only $5.7 \%$ from class $1,6.8 \%$ from class $2,6.1 \%$ from class 3 and $6 \%$ from class 4 . Only $8.6 \%$ of the participants in class 1 ever had a mammogram, $12.5 \%$ from class $2,12.2 \%$ from class 3 and $7.7 \%$ from class $4.91 \%, 93 \%, 95.3 \%$ and $97.2 \%$ women from classes 1, 2, 3 and 4 were willing to perform monthly BSE if they were taught properly.

Table 1: Frequency distribution of the demographic characteristics.

\begin{tabular}{lll}
\hline Variable & & Frequency $(\%)$ \\
\hline \multirow{2}{*}{ Age } & Mean & 31.5 \\
& Range & $18-60$ \\
\hline \multirow{2}{*}{ Marital status } & Ever married & $237(47)$ \\
& Never married & $267(53)$ \\
\hline \multirow{3}{*}{ House income } & Less than PKR 10,000 & $35(6.9)$ \\
& PKR 10,000-30,000 & $88(17.5)$ \\
& PKR 30,000-60,000 & $150(29.8)$ \\
& More than PKR 60,000 & $231(45.8)$ \\
\multirow{2}{*}{ Level of Education } & No formal education & $69(13.7)$ \\
& Primary education & $20(4)$ \\
& Matriculation & $30(6)$ \\
\multirow{2}{*}{ Family history of disease } & College & $72(14.3)$ \\
& University & $313(62.1)$ \\
\hline
\end{tabular}

Table 2: Mean Knowledge, Attitude and Practice scores.

\begin{tabular}{lllllll}
\hline Variable & Class 1 (\%) & Class 2 (\%) & Class 3 (\%) & Class 4 (\%) & Mean (\%) & P value \\
\hline $\begin{array}{l}\text { Knowledge } \\
\text { score }\end{array}$ & 37.8 & 44.4 & 62.7 & 66.47 & 52.9 & 0.000 \\
Attitude score & 84.85 & 90.68 & 89.8 & & & \\
Practice score & 32.1 & 37 & 36.42 & 36.1 & 88.23 & 0.000 \\
\hline
\end{tabular}

Table 3: Attitudes and Practices of the women regarding breast cancer screening.

\begin{tabular}{ll}
\hline Variable & Percent people \\
\hline People who performed a BSE every month & 5.7 \\
Class 1 & 6.8 \\
Class 2 & 6.1 \\
Class 3 & 6 \\
Class 4 & \\
\hline Women who ever performed a BSE & 45.7 \\
Class 1 & 50 \\
Class 2 & 43.2 \\
Class 3 & 34.8 \\
Class 4 & \\
\hline Women who said they will perform regular BSE if theyknew how & 91 \\
Class 1 & 93 \\
Class 2 & 95.3 \\
Class 3 & 97.2 \\
Class 4 & 8.6 \\
\hline Women who ever had a mammogram & 12.5 \\
Class 1 & 12.2 \\
Class 2 & 7.7 \\
\hline Class 3 & \\
\hline
\end{tabular}




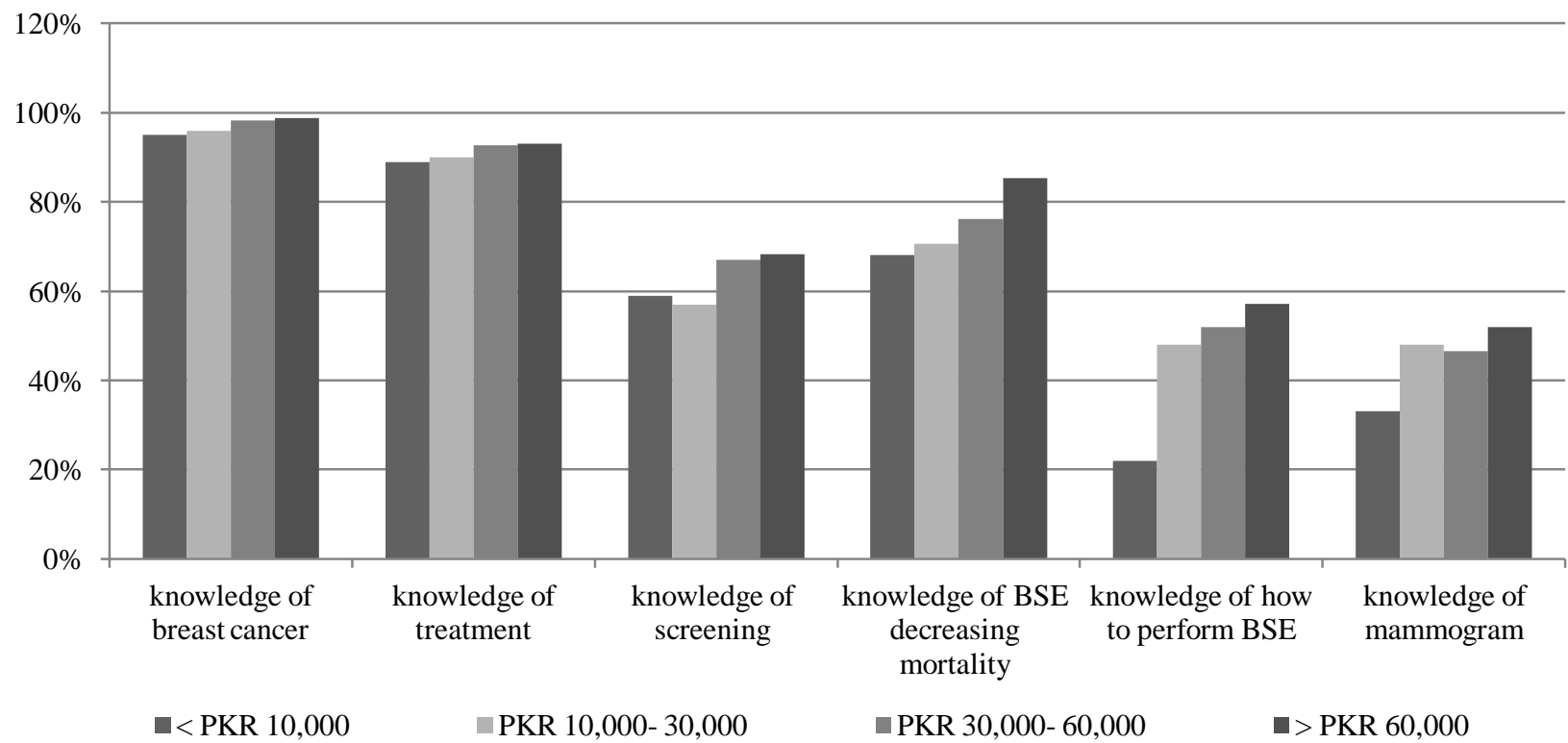

Fig. 1: Knowledge of breast cancer.

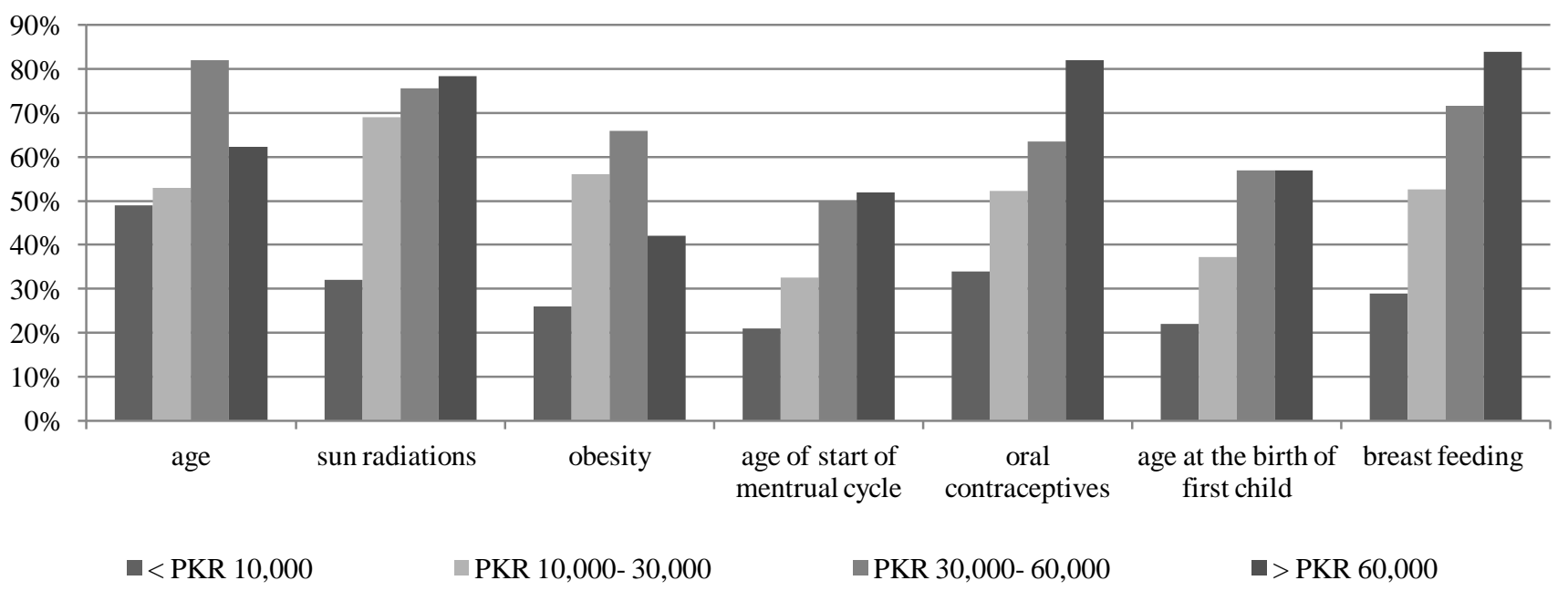

Fig. 2: Knowledge of breast cancer risk factors.

\section{DISCUSSION}

The majority of the participants have had some form of a formal education and about half of total belonged to the group having a monthly household income of more than PKR 60,000. The mean knowledge about breast cancer screening and its risk factors was insufficient in all the participants (Table 2). Previous studies have shown a similar lack of knowledge in Asian women (Ahmed et al., 2006; Choudhry et al., 1998). However, there was a statistically significant difference in the knowledge of the women in all four groups with the amount of knowledge they had about breast cancer, its screening and risk factors increasing as the monthly household income increased. Similar cases have been reported for most Asian and African countries(Rashidi and Rajaram, 2000; Haji-Mahmoodi et al., 2002; Okobia et al., 2006; Heidari et al., 2008).

Most of the people knew what breast cancer was and that it can be treated but fewer people knew about breast cancer screening (Figure 3). Knowledge about BSE decreasing the mortality rate increased with the increase in the socio-economic class; however, very few knew exactly how to perform a BSE. Knowledge of the risk factors of breast cancer showed an 
increasing trend with an increase in the monthly household income (Figure 2). Age of the start of the menstrual cycle and age at the time of the birth of a first child were the risk factors women knew the least about. Increasing age and avoiding breast feeding increasing the chances of getting breast cancer were most commonly known (Abedzadeh et al., 2003; Amin et al., 2009; Grunfeld et al., 2002). The attitude and practices regarding breast cancer seemed to be independent of the monthly household income and were low on average (Table 2), this is in line with previous findings (Odusanya, 2001). The attitude scores of the four groups were significantly different but there was no general trend towards increasing or decreasing monthly income (O'Malley et al., 2001; Lannin et al., 2002; Zapka et al., 1989). Participants who were educated on how to perform a BSE from all 4 classes had strong intentions of practicing it on regular basis from then onwards.

\section{CONCLUSION}

The study concludes that there is a lack of awareness of breast cancer screening methods and risk factors in women of Lahore. The lack of knowledge is particularly true for women belonging to low socio-economic status., the study also showed that the women who did know about the risks of breast cancer and screening decreasing mortality rates made little or no effort to learn to perform the screening tests. After being reminded and being taught the screening procedures most women did show the willingness and intent to perform regular breast self-exams. The study hence highlights not only the importance of educating women of all socio-economic classes on such health issues but also emphasizes the importance of practical teaching and constant reminders through media led education campaigns, medical seminars, specific counseling and other methods.

\section{ACKNOWLEDGEMENTS}

We are thankful to the University College of Pharmacy for their support. We also appreciate the efforts of Anum Akram and Myeda Saeed in helping collect the data.

\section{CONFLICT OF INTEREST}

The authors have no conflict of interest.

\section{REFERENCES}

Abedzadeh Masoume, Sadat, Zohreand Saberi Farzane. Knowledge, attitude, and performance of women referring health care centers in Kashan towards breast cancer and its screening tests. Journal of Kashan University of Medical Sciences (FEYZ), 2003; 7(2), 85-92.

Agarwal Gaurav, Pradeep PV, Aggarwal Vivek, Yip ChengHar, and Cheung Polly SY. Spectrum of breast cancer in Asian women. World Journal of Surgery, 2007;31(5), 1031-1040.

Ahmed Faiza, Mahmud Sadia, Hatcher Juanita and Khan Shaista M. Breast cancer risk factor knowledge among nurses in teaching hospitals of Karachi, Pakistan: a cross-sectional study. BMC nursing, 2006;5(1), 1 .

Amin TT, Al Mulhim AR, and Al Meqihwi A. Breast cancer knowledge, risk factors and screening among adult Saudi women in a primary health care setting. Asian Pacific Journal of Cancer Prevalence, $2009 ; 10(1), 133-138$

Azaiza Faisal and Cohen Miri . Health beliefs and rates of breast cancer screening among Arab women. Journal of Women's Health,2006; 15(5), 520-530.

Azaiza Faisal, and Cohen Miri . Between traditional and modern perceptions of breast and cervical cancer screenings: a qualitative study of Arab women in Israel. Psycho-Oncology, 2008;17(1), 34-41.

Bhurgri Yasmin, Bhurgri Asif, Hassan Sheema H, Zaidi SHM, Rahim Abdul, Sankaranarayanan Rengaswamy et al. Cancer incidence in Karachi, Pakistan: first results from Karachi cancer registry. International Journal of Cancer, 2008; 85(3): 325-329.

Choudhry Ushvendra Ushi, Srivastava Rani, and Fitch Margaret I. Breast cancer detection practices of South Asian women: Knowledge, attitudes and beliefs. Oncology Nursing Forum, 1998; 25(10):1693-701.

Colditz Graham A, and Rosner Bernard . Cumulative risk of breast cancer to age 70 years according to risk factor status: data from the Nurses' Health Study. American Journal of Epidemiology, 2000;152(10), 950-964.

Dandash Khadiga F, and Al-Mohaimeed Abdurrahman. Knowledge, attitudes, and practices surrounding breast cancer and screening in female teachers of Buraidah, Saudi Arabia. International Journal of Health Sciences (Qassim), 2007; 1(1), 61-71.

DeSantis C., Siegel R., Bandi P., andJemal, A. (2011). Breast cancer statistics. CA: A Cancer Journal for Clinicians, 2011; 61(6), 408 418.

Ferlay Jacques, Shin Hai-Rim, Bray Freddie, Forman David, Mathers Colin, andParkin Donald Maxwell. Estimates of worldwide burden of cancer in 2008: GLOBOCAN 2008. International Journal of Cancer,2010; 127(12), 2893-2917.

Ferlay J., Héry C., Autier P., Sankaranarayanan R. Global Burden of Breast Cancer. In: Li C. (eds) Breast Cancer Epidemiology, 2010; Springer, New York, NY.

Flórez Karen R, Aguirre Alejandra N, ViladrichAnahí, CéspedesAmarilis, De La Cruz Ana Alicia, andAbraído-Lanza Ana F. Fatalism or destiny? A qualitative study and interpretative framework on Dominican women's breast cancer beliefs. Journal of Immigrant and Minority Health, 2009; 11(4), 291-301.

Grunfeld EA, Ramirez AJ, Hunter MS, and Richards MA. Women's knowledge and beliefs regarding breast cancer. British Journal of Cancer,2002; 86(9), 1373-1378.

Haji-Mahmoodi, Mehregan Montazeri, Ali Jarvandi, Soghra Ebrahimi, Mandana Haghighat Shahpar, and Harirchi Iraj. . Breast Self-Examination: Knowledge, Attitudes, and Practices Among Female Health Care Workers in Tehran, Iran. The Breast Journal, 2002; 8(4), 222225.

Heidari, Z, Mahmoudzadeh-Sagheb, HR, andSakhavar, N. Breast cancer screening knowledge and practice among women in southeast of Iran. Acta Medica Iranica, 2008; 46(4), 321-328.

Jatoi Ismail. Breast cancer screening. The American Journal of Surgery, 1999; 177(6), 518-524.

Lannin Donald R, Mathews Holly F, Mitchell Jim, and Swanson Melvin S. Impacting cultural attitudes in African-American women to decrease breast cancer mortality. The American Journal of Surgery, 2002; 184(5), 418-423.

Ma Jiemin and Jemal Ahmedin . Breast cancer statistics Breast Cancer Metastasis and Drug Resistance Springer,2013;1-18

Madigan M Patricia, Ziegler Regina G, Benichou Jacques, Byrne Celia, and Hoover Robert N. Proportion of breast cancer cases in the United States explained by well-established risk factors. Journal of the National Cancer Institute,1995; 87(22), 1681-1685.

McPherson Klim, Steel CM, and Dixon JM. Breast cancerepidemiology, risk factors, and genetics. British Medical Journal, 2000; 321(7261), 624-628.

Mitchell Jim, Lannin Donald R, Mathews Holly F, and Swanson Melvin S. Religious beliefs and breast cancer screening. Journal of Women's Health,2002; 11(10), 907-915. 
Montazeri Ali, Vahdaninia Mariam, HarirchiIraj, Harirchi Amir Mahmood, Sajadian Akram, Khaleghi Fatemeh, et al. Breast cancer in Iran: need for greater women awareness of warning signs and effective screening methods. Asia Pacific Family Medicine, 2008; 7(1): 6.

O'Malley Michael S, Earp Jo Anne, Hawley Sarah T, Schell Michael J, Mathews Holly F, and Mitchell Jim. The association of race/ethnicity, socioeconomic status, and physician recommendation for mammography: who gets the message about breast cancer screening? American Journal of Public Health, 2001; 91(1): 49.

O. Odusanya, Olufemi O. Tayo Olumuyiwa. Breast cancer knowledge, attitudes and practice among nurses in Lagos, Nigeria. Acta Oncologica, 2001; 40(7), 844-848.

Okobia Michael N, Bunker Clareann H, Okonofua Friday E, and Osime Usifo . Knowledge, attitude and practice of Nigerian women towards breast cancer: a cross-sectional study. World Journal of Surgical Oncology, 2006;4:11 doi:10.1186/1477-7819-4-11.

Parsa Parisa, and Kandiah Mirnalini. Breast cancer knowledge, perception and breast self-examination practices among Iranian women. The International Medical Journal, 2005; 4(2), 17-24.

Peters DH, Garg A, Bloom G, Walker DG, Brieger WR, Rahman MH . Poverty and access to health care in developing countries. Annals of the New York Academy of Sciences, 2008; 1136: 161-171.

Rashidi Anahita and Rajaram Shireen S. Middle Eastern Asian Islamic women and breast self-examination: needs assessment. Cancer Nursing, 2000; 23(1), 64-70.
Sim HL, Seah M, and Tan SM. Breast cancer knowledge and screening practices: a survey of 1,000 Asian women. Singapore Medical Journal, 2009; 50(2), 132.

Tabár L, Fagerberg CJ, Gad A, Baldetorp L, Holmberg LH, Gröntoft $\mathrm{O}$ et al. Reduction in mortality from breast cancer after mass screening with mammography: randomised trial from the Breast Cancer Screening Working Group of the Swedish National Board of Health and Welfare. The Lancet, 1985; 325(8433): 829-832.

Underwood SM, Shaikha L, and Bakr D. Veiled yet vulnerable. Breast cancer screening and the Muslim way of life. Cancer practice, 1998; 7(6): 285-290.

Zapka Jane G, Stoddard Anne M, Costanza Mary E, and Greene Harry L. Breast cancer screening by mammography: utilization and associated factors. American Journal of Public Health, 1989; 79(11): 1499-1502.

\section{How to cite this article:}

Rizwan A, Saleem Z, Sadeeqa S. Effect of Family Income on Knowledge, Attitude and Practices Regarding Breast Cancer and its Screening Methods Amongst Women of Lahore, Pakistan. J App Pharm Sci, 2017; 7 (08): 028-033. 